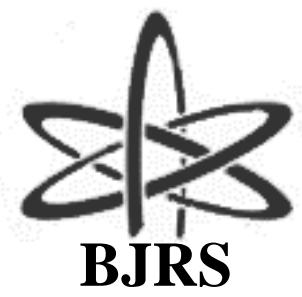

BRAZILIAN JOURNAL

$\mathrm{OF}$

RADIATION SCIENCES

09-01 (2021) 01-15

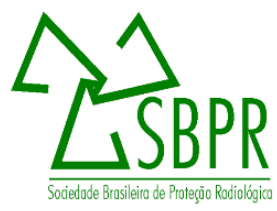

\title{
Computational simulation of low energy $x$-ray source for photodynamic therapy: a preliminary study
}

\author{
Souza ${ }^{a}$ L.S., Alva-Sánchez ${ }^{\mathrm{b}}$ M.S., Bonatto ${ }^{\mathrm{b}}$ A. \\ ${ }^{a}$ Medical Physics course/ Federal University of Health Sciences of Porto Alegre, Rua Sarmento Leite, 245 -CEP \\ 90050-170- Porto Alegre, Rio Grande do Sul, Brazil \\ ${ }^{b}$ Department of Exact and Applied Social Sciences / Federal University of Health Sciences of Porto Alegre, Rua \\ Sarmento Leite, 245 -CEP 90050-170- Porto Alegre, Rio Grande do Sul, Brazil \\ leandroso@ufcspa.edu.br
}

\begin{abstract}
Photodynamic therapy is a therapeutic modality capable of selectively inducing cytotoxic effects in malignant cells. Such effects are obtained by using a laser or a lamp as a light source to irradiate a previously-delivered photosensitizer into the tumoral cells. Since clinical application of photodynamic therapy depends on light penetration, lasers and lamps can only be used for shallow tissue treatment. To overcome this limitation, $x$-ray induced photodynamic therapy has been recently proposed. The goal of this work is to investigate the $x$-ray interactions in a medium containing a homogeneous concentration of distinct photosensitizers. This is achieved by evaluating the relative doses and energy spectra, obtained at distinct depths by means of Monte Carlo simulations. Preliminary results for the relative dose showed a minor dose increase, of approximately $0.15 \%$, when photosensitizers are used. In addition, $x$-ray interactions with the investigated photosensitizers mostly occur from photons with energies below $60 \mathrm{keV}$.
\end{abstract}

Keywords: photodynamic therapy, radiotherapy, Monte Carlo, TOPAS, x-rays. 


\section{INTRODUCTION}

Photodynamic therapy (PDT) is a clinically-approved, minimally-invasive procedure for treating cancer and other shallow-tissue diseases. For example, PDT has been successfully used in dermatology and in the treatment of glioblastoma, mesothelioma, and prostate [1]. PDT is a process in which a previously-delivered photosensitizer at the malignant cells is irradiated by a light source. If a proper wavelength is chosen, light absorption occurs, exciting the photosensitizer to a singlet state. From this state, an intersystem crossing can lead the photosensitizer to a triplet state, enabling Type I or Type II reactions. Both reactions produce multiple reactive oxygen species, causing a selectively cytotoxic effect in the target tissue [2-6]. Figure 1 shows a schematic description of the aforementioned PDT working principle [2].

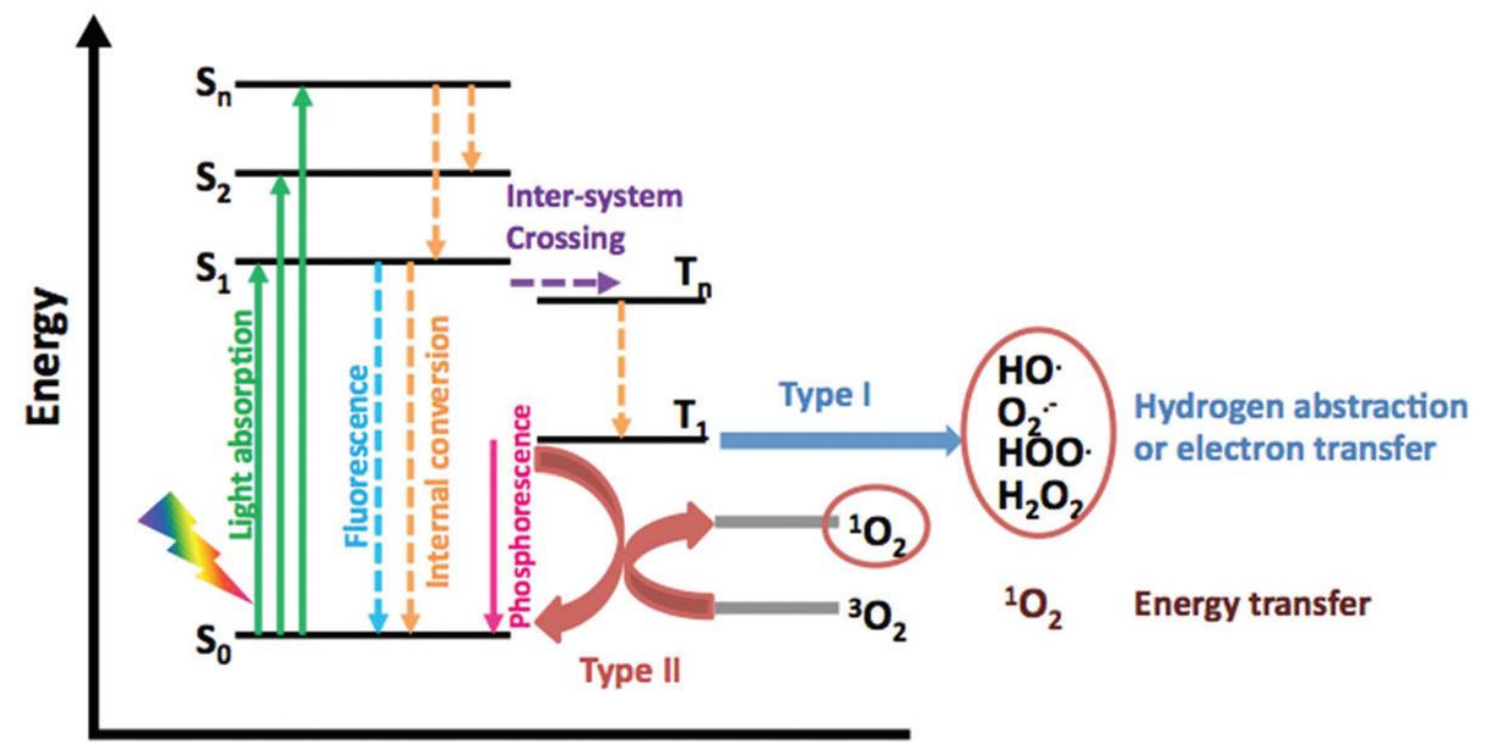

Figure 1: Illustration of the photodynamic process [2].

Most of the photosensitizers used in PDT have a tetrapyrrole structure, similar to the protoporphyrin in the hemoglobin. The photosensitizers should have chemical purity, selective accumulation in neoplastic tissue, short biological half-life, high capacity to generate many cytotoxic products, and an optimal absorption with wavelengths between $600 \mathrm{~nm}$ and $800 \mathrm{~nm}$ [1, 68]. 
PDT treatment is usually carried out using lasers or lamps as light sources. While lasers have narrow bands in the energy spectrum, with high power output, lamps, on the other hand, have a wider spectrum, and lower power output. Despite these poorer spectral properties, lamps can offer advantages in comparison to lasers, such as, for example, lower cost and complexity. In addition, since lamps usually have larger spot sizes than those of lasers, they are more suitable for treating larger superficial lesions. However, since both lasers and lamps have low penetration into tissue, PDT treatment is limited to superficial lesions if these light sources are adopted [9].

To overcome this limitation, the use of $\mathrm{x}$-rays as a light source in PDT has been proposed. So far, there are three techniques using this approach: radiodynamic therapy (RDT), nanoscintillatormediated x-ray inducible photodynamic therapy, and x-ray induced photodynamic therapy (xPDT). The RDT is a combination of conventional PDT and radiotherapy, where two light sources are used, lasers and x-rays. In the second one, a nanoscintillator is used to convert the $\mathrm{x}$-ray irradiation into visible light, which can then interact with the photosensitizer to produce the cytotoxic effect. The $\mathrm{xPDT}$ is the focus of this work, in which the $\mathrm{x}$-rays directly activate the photosensitizer, in order to generate the reactive oxygen species [2]. Due to the physical properties of x-rays, photons would be able to reach deeper tissues, expanding PDT applications beyond the conventional optical window. Although previous XPDT studies can be found in the literature [10-20], evaluating the role played by the photosensitizers in the presented results - specially the experimental ones - is a far from trivial task. Since information about the physical interactions between the $\mathrm{x}$-rays and photosensitizers is sparse, and results in the absence of these photosensitizing agents are not always presented, numerically modelling and evaluating such interactions may provide useful information for optimizing the xPDT. The goal of this work is to investigate the interaction of $x$-rays in a medium containing a homogeneous concentration of distinct photosensitizers, with aid of the Tool for Particle Simulation, or TOPAS. TOPAS is an innovative Monte Carlo platform for research and clinical applications, which wraps and extends the Geant4 Simulation Toolkit. By using TOPAS, a parameter control system can be configured to simulate a wide variety of radiotherapy applications, with no prior knowledge required on the underlying Geant4 Simulation Toolkit or any programming language [21]. 


\section{MATERIALS AND METHODS}

\subsection{Simulation validation}

A Monte Carlo code, TOPAS, was used in this work. To validate the simulations, the following conditions were adopted: $2 \times 2 \mathrm{~cm}^{2}$ field size and source-surface-distance at $100 \mathrm{~cm}$, with a $150 \mathrm{kV}$ spectrum, and a $50 \mathrm{keV}$ monoenergetic $\mathrm{x}$-ray source as well. The simulated phantom was a water cube of $30 \times 30 \times 30 \mathrm{~cm}^{3}$. The $150 \mathrm{kV}, 4 \mathrm{~mm} \mathrm{Al}$, and $20^{\circ}$ spectrum was obtained by using SpekCalc [22], a software that calculates photon spectra from tungsten anode x-ray tubes. To assess the simulations, percentage depth dose curves were plotted and compared with data obtained from literature [23].

\subsection{Modeling strategy}

Figure 2 shows how this work is organized. There are three simulation setups, divided into two scenarios. In the first setup, a cylindrical phantom with $17 \mathrm{~cm}$ diameter and $22 \mathrm{~cm}$ height, containing spherical tumors of $1 \mathrm{~cm}$ diameter, is adopted. Both the phantom and the tumors are filled with soft tissue [24]. In the second setup, all the conditions were maintained, with exception of the tumors, which are now filled with a homogeneous mixture of soft tissue and photosensitizer. For each simulation, the spherical objects representing the tumors are placed at distinct depths, ranging from $0.5 \mathrm{~cm}$ to $9.5 \mathrm{~cm}$ from the top of the cylinder. Finally, in the second scenario (third setup), the tumors were removed, and each phantom was homogeneously filled with a given photosensitizer. Although this scenario has no practical application, it has been adopted in order to investigate the $\mathrm{x}$-ray interactions in a homogeneously distributed media containing each of the photosensitizers. For all cases, a $2 \times 2 \mathrm{~cm}^{2}$ field size, a source-surface-distance of $40 \mathrm{~cm}$, and a 150 $\mathrm{kV}$-ray source, with an effective energy of $50 \mathrm{keV}$, were adopted as the simulated irradiation conditions [25]. The response of the interaction was evaluated through the relative doses and spectral energy distributions obtained at distinct depths. 


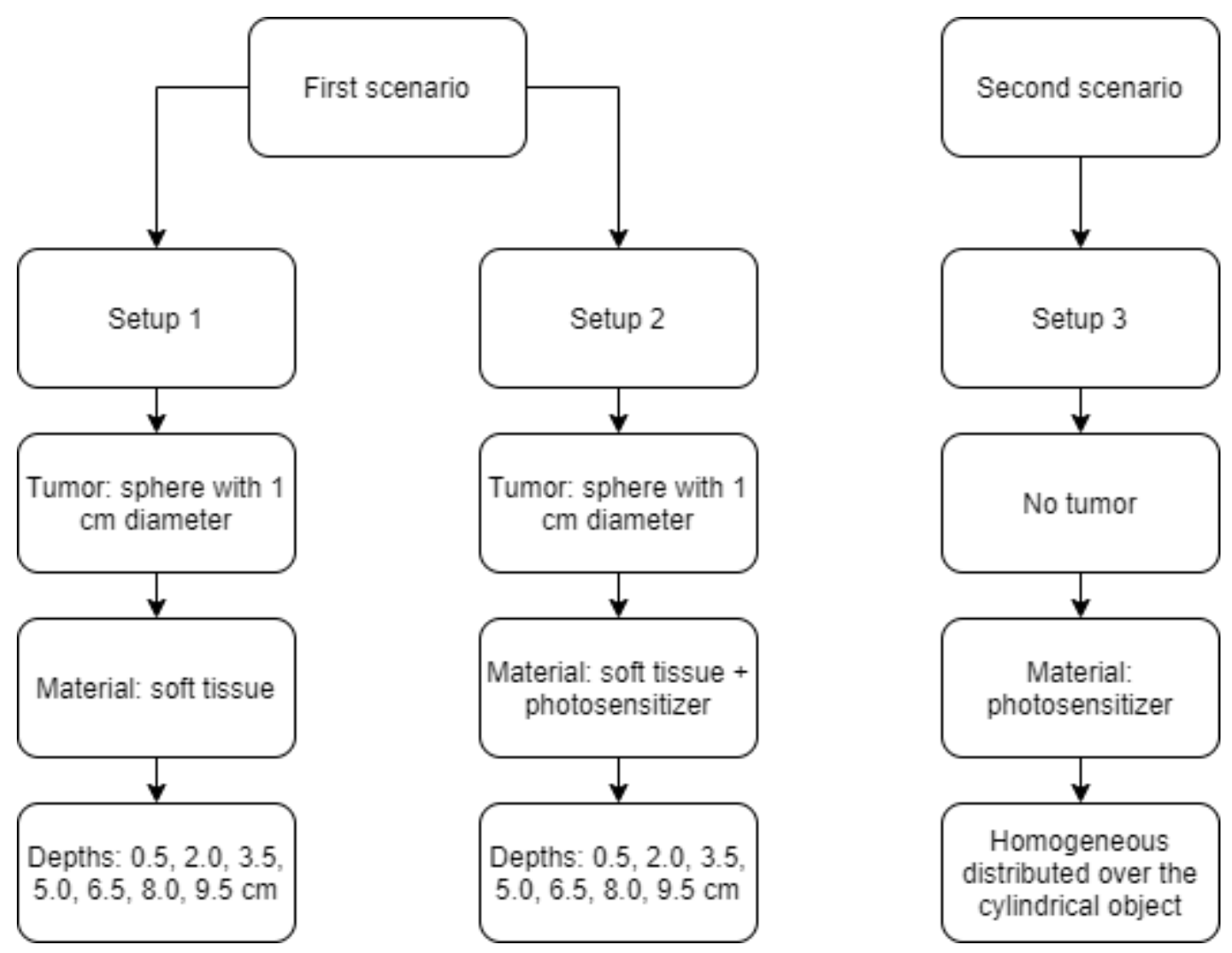

Figure 2: Modelling strategy.

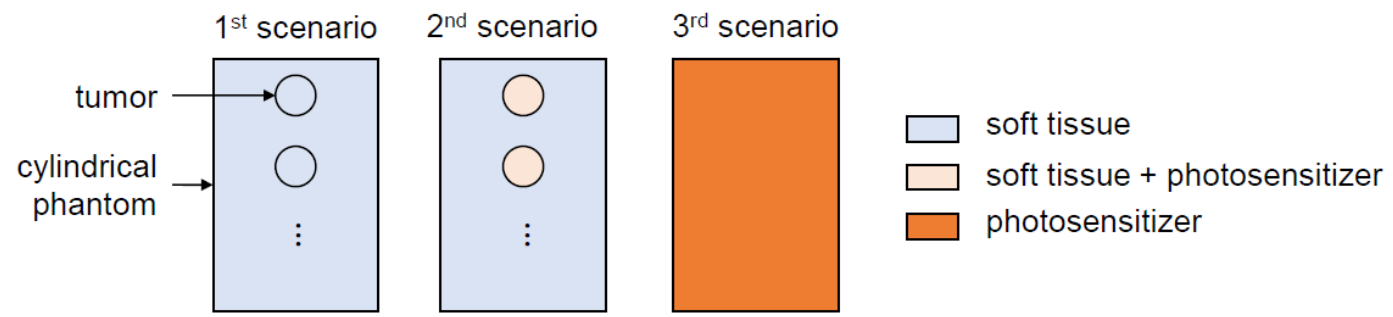

Figure 3: Schematic representation (not in scale) of the investigated scenarios. The circular object depicts the tumor, and the rectangular object portrays the cylindrical phantom. The colors represent the filling materials. The multiple circles shown in the first and second scenarios indeed represent the same tumor, placed at distinct positions. Each simulation for such scenarios contains a single tumor, placed at a given depth from the top of the cylinder.

In the first scenario, the mean dose deposition inside the tumors was obtained and a dose increase factor (DIF) was calculated: 


$$
D I F=\frac{\text { Total mean dose deposition with photosensitizer }}{\text { Total mean dose deposition without photosensitizer }}
$$

\subsection{Photosensitizers composition}

All the information about the chemical composition of the photosensitizers were obtained in the database PubChem. For the soft tissue, the NIST database was used (Table 1) [26, 27]. The mixture of soft tissue and photosensitizer was calculated by using a weighted average sum of the chemical elements in the composition. For each existing chemical element $C_{j}$ in the mixture, the weight fraction $W_{m i x, j}$ is calculated as follows,

$$
W_{m i x, j}=\frac{\sum_{i} n_{i} W_{i j}}{\sum_{i} n_{i}},
$$

where $W_{i j}$ is the weight fraction of $C_{i j}$, the $j^{t h}$ chemical element of the $i^{\text {th }}$ material $M_{i}$ present in the mixture. Regarding the mixture density $n_{m i x}$, it is calculated by summing the individual densities $n_{i}$ of the mixed materials, $n_{\text {mix }}=\sum_{i} n_{i}$.

Table 1: Materials

\begin{tabular}{cccc}
\hline Material $\boldsymbol{M}_{\boldsymbol{i}}$ & $\begin{array}{c}\text { Density } \boldsymbol{n}_{\boldsymbol{i}} \\
\left(\mathbf{k g} / \mathbf{m}^{\mathbf{3}}\right)\end{array}$ & $\begin{array}{c}\text { Chemical element } \\
\boldsymbol{C}_{\boldsymbol{i} \boldsymbol{j}}\end{array}$ & $\begin{array}{c}\text { Weight fraction } \\
\boldsymbol{W}_{\boldsymbol{i} \boldsymbol{j}}\end{array}$ \\
\hline & Hydrogen & 0.105 \\
Carbon & 0.256 \\
Soft tissue & Nitrogen & 0.027 \\
& \multirow{3}{*}{1030} & Oxygen & 0.602 \\
& & Sodium & 0.001 \\
& & Phosphor & 0.002 \\
& & Sulfur & 0.003 \\
& & Chlorine & 0.002 \\
& & Potassium & 0.002 \\
& & & 0.071 \\
& & Hydrogen & 0.769
\end{tabular}




\begin{tabular}{cccc}
\hline Material $M_{\boldsymbol{i}}$ & $\begin{array}{c}\text { Density } \\
\left(\mathbf{k g} / \mathbf{m}^{\mathbf{3}}\right)\end{array}$ & $\begin{array}{c}\text { Chemical element } \\
\boldsymbol{C}_{\boldsymbol{i} \boldsymbol{j}}\end{array}$ & $\begin{array}{c}\text { Weight fraction } \\
\boldsymbol{W}_{\boldsymbol{i} \boldsymbol{j}}\end{array}$ \\
\hline & & \\
& & \\
& & 0.056 \\
Methylene Blue & Hydrogen & 0.600 \\
& 0.0515 & Carbon & 0.109 \\
& & Chlorine & 0.131 \\
& & Nitrogen & 0.100 \\
\hline
\end{tabular}

*Although the acridine orange is known to be toxic at higher concentrations [28], it was chosen in this simulation due to its better response as a photosensitizer, if compared to other substances [11-20].

\section{RESULTS AND DISCUSSION}

Regarding the validation of the presented simulations, Figure 3 shows a percentage depth dose curve of experimental data [23], compared to TOPAS simulation results. While the experimental data was obtained from a $50 \mathrm{keV}$ monoenergetic $\mathrm{x}$-ray, two distinct TOPAS simulations were performed. In the first simulation, in order to match the experimental data setup, a $50 \mathrm{keV}$ monoenergetic x-ray was adopted. In addition, a second simulation, using a $150 \mathrm{kV}$ x-ray energy spectrum, was performed. Since $50 \mathrm{keV}$ is the effective energy for the $150 \mathrm{kV}$ spectrum, a similar behavior between both simulations is expected. Indeed, Figure 3 shows a reasonable agreement between the simulation results, and between each simulation and the experimental data as well. Figure 4 shows that the differences between the TOPAS simulation results and experimental data lay within the range of the uncertainty associated to such experimental results. 


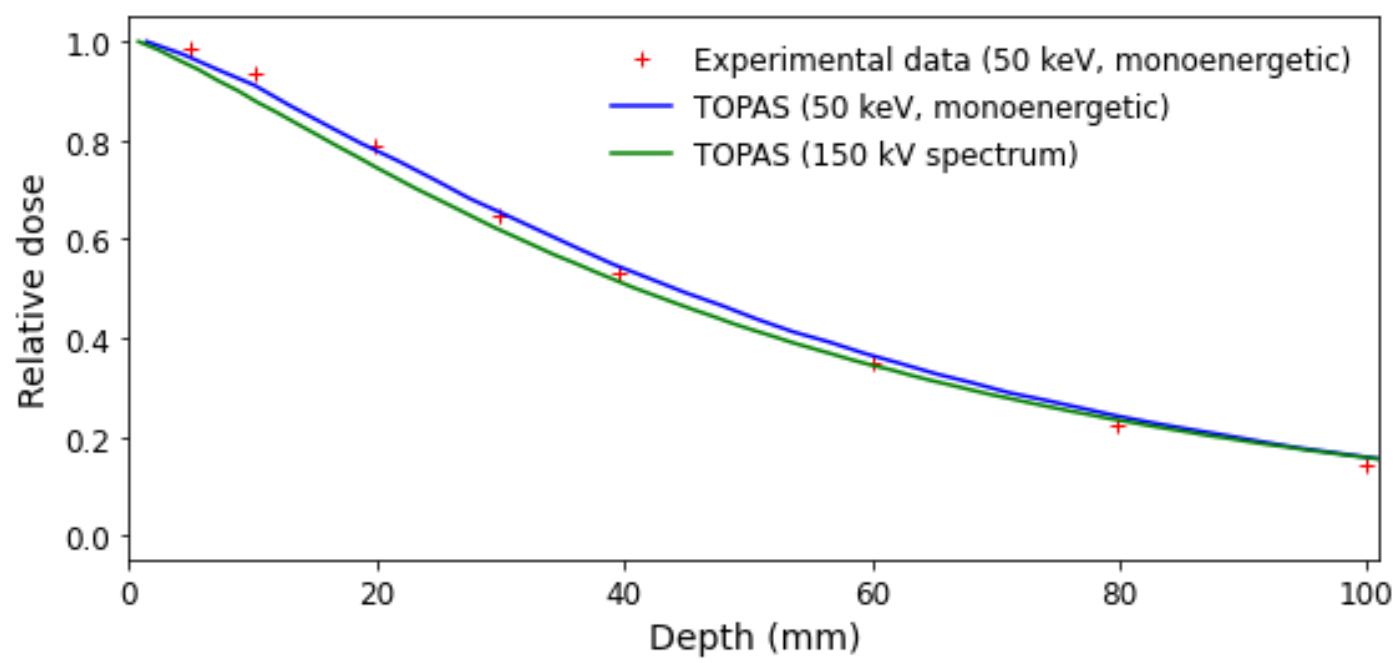

Figure 4: Comparison of the percentage depth dose curve from TOPAS simulation results and experimental data. Since the highest standard deviation from TOPAS results was approximately $3.55 \times 10^{-7} \mathrm{~Gy}$, no error bars were plotted.

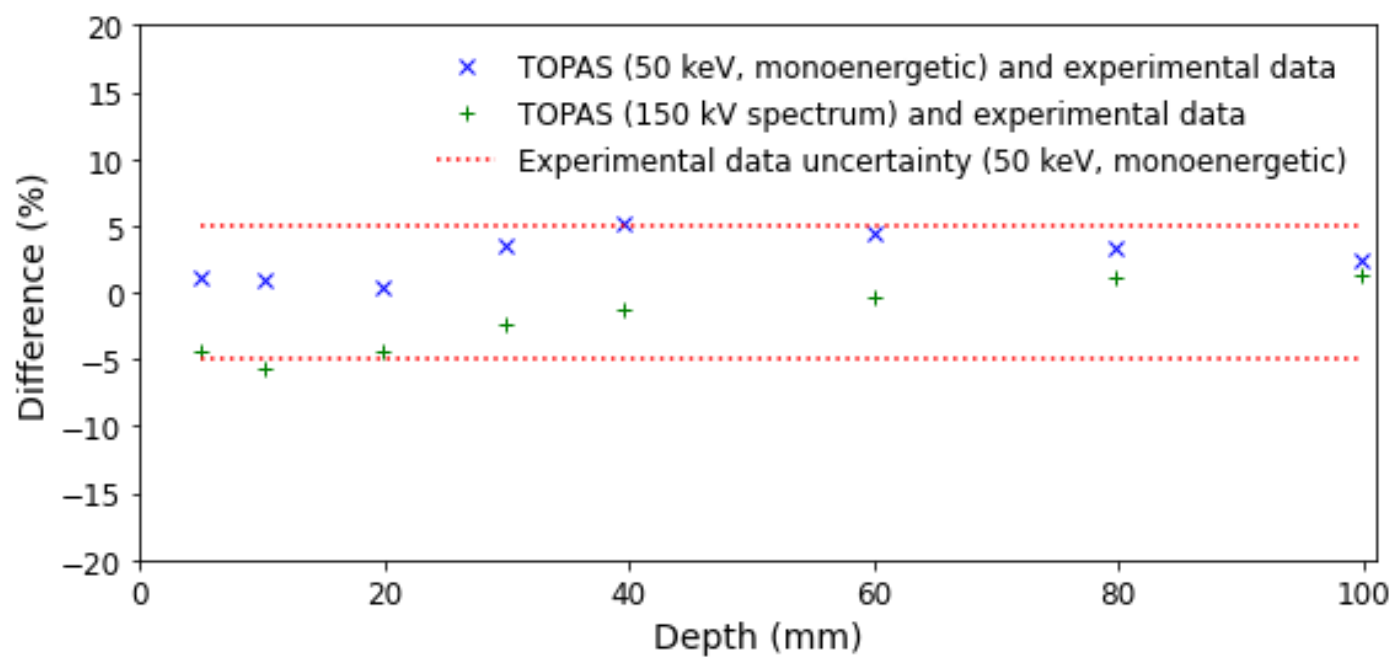

Figure 5: The differences between simulation results and experimental data. are within the uncertainty (red dotted lines) associated with such experimental results [23].

The dose increase factors obtained for the seven evaluated depths are shown in Figure 5. From this Figure, one can conclude that, for both photosensitizers, no significant improvement in the dose deposition is observed. Moreover, simulation results show that only a small fraction of x-ray photons interacted with the photosensitizers, by means of the photoelectric and Compton effects. As a consequence, $x$-ray spectra obtained for distinct photosensitizers are nearly indistinguishable. An 
alternative method to compare the $\mathrm{x}$-ray interactions with distinct photosensitizers is by evaluating the energy spectra of the secondary electrons produced by such interactions. Since the yield of secondary electrons is proportional to the x-ray interactions, subtle differences should be clearly visible in their energy spectra. In order to check the feasibility of this method, the energy spectra of secondary electrons were evaluated for the second-scenario simulations (homogeneously-filled cylinders with photosensitizers, as described in Figure 2). Figures 6, 7, and 8 show these energy spectra, obtained at the top $(0 \mathrm{~cm})$, middle $(5 \mathrm{~cm})$, and bottom $(9 \mathrm{~cm})$ regions of the cylinder. At the top, both cases show similar results. Since the $\mathrm{x}$-rays have just reached the medium, this behavior is expected. At the middle of the cylinder, the yield of electrons with energies below $20 \mathrm{keV}$ is higher for the acridine orange, if compared to the methylene blue. From approximately $20 \mathrm{keV}$ to $60 \mathrm{keV}$, the production of secondary electrons fades to zero. From the middle to the bottom of the phantom, this behavior remains unchanged for both photosensitizers. Regarding the interactions between $\mathrm{x}$ rays and the photosensitizers, the higher yield of secondary electrons observed for the acridine orange suggests that this photosensitizer may preferable over the methylene blue for xPDT application. However, this is an oversimplified analysis. The choice of a proper photosensitizer involves many additional parameters, such as the optimal absorption in the optical window, and a high-production of reactive oxygen species, which are not under consideration in this work.

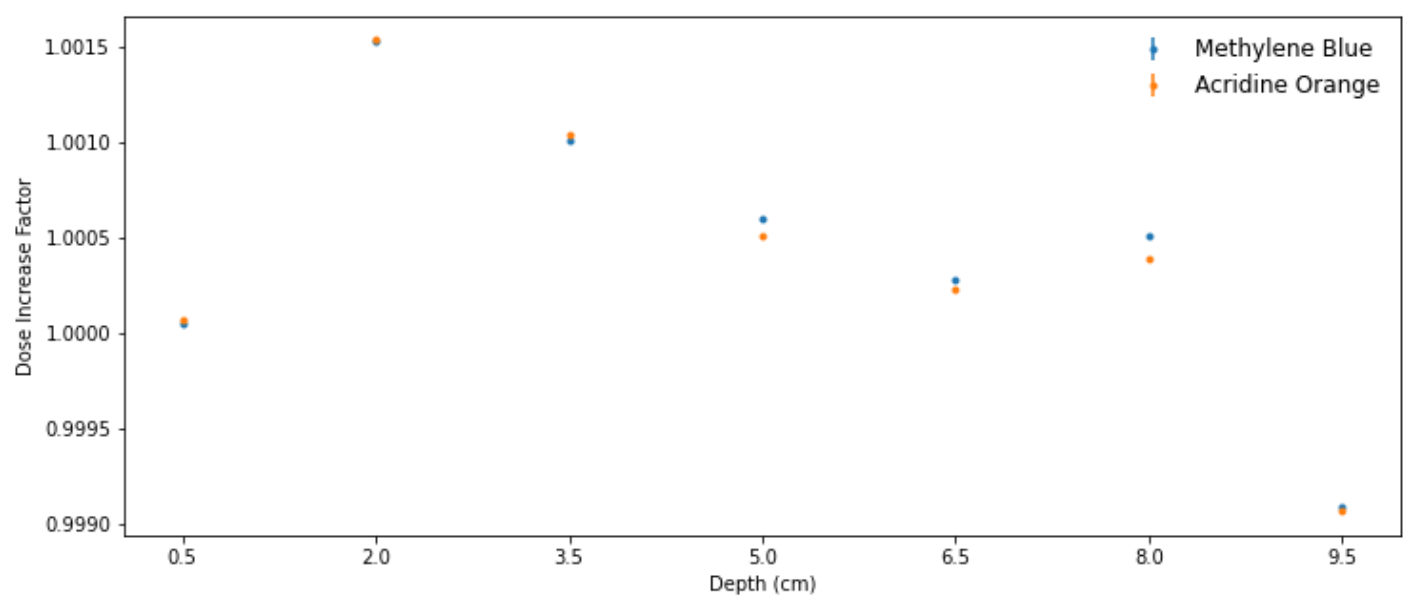

Figure 6: Dose increase factor at distinct depths, obtained for the first scenario. The highest standard deviation was approximately $2.15 \times 10^{-9}$ Gy. These results were obtained in the first scenario. 


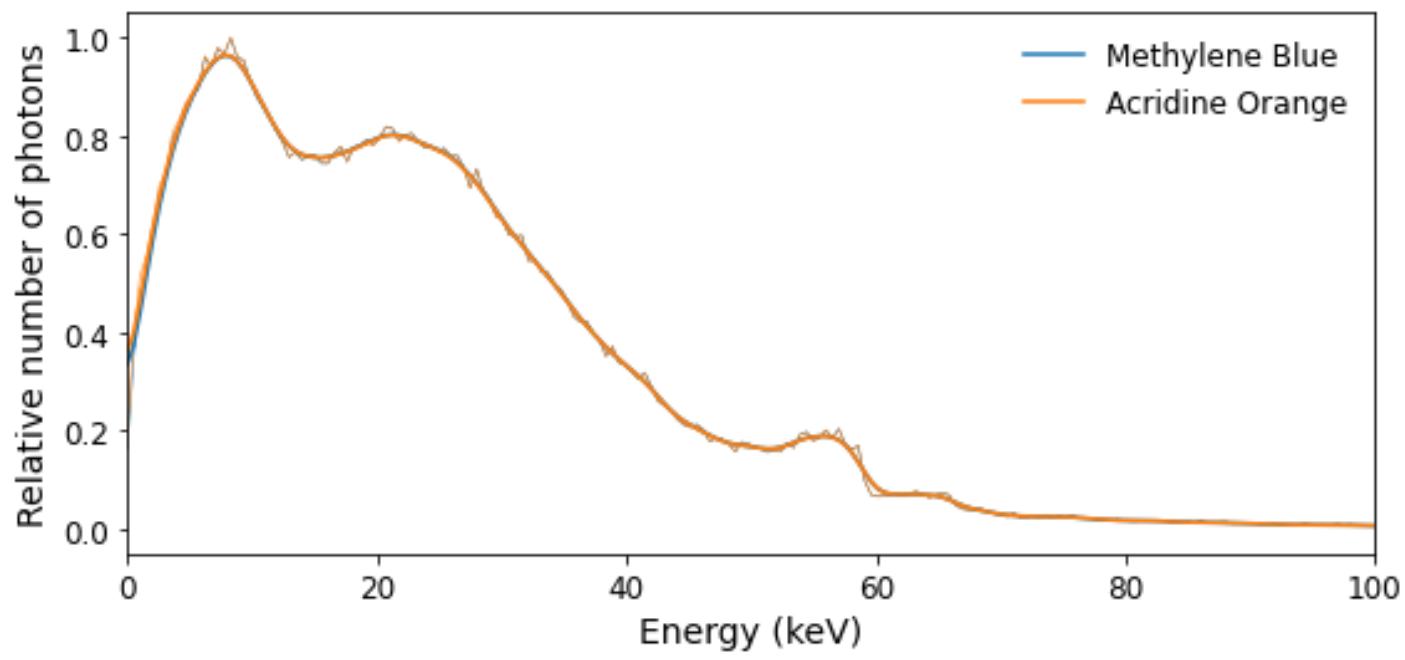

Figure 7: Energy spectrum of the secondary electrons at $0.0 \mathrm{~cm}$ depth, obtained for the second scenario.

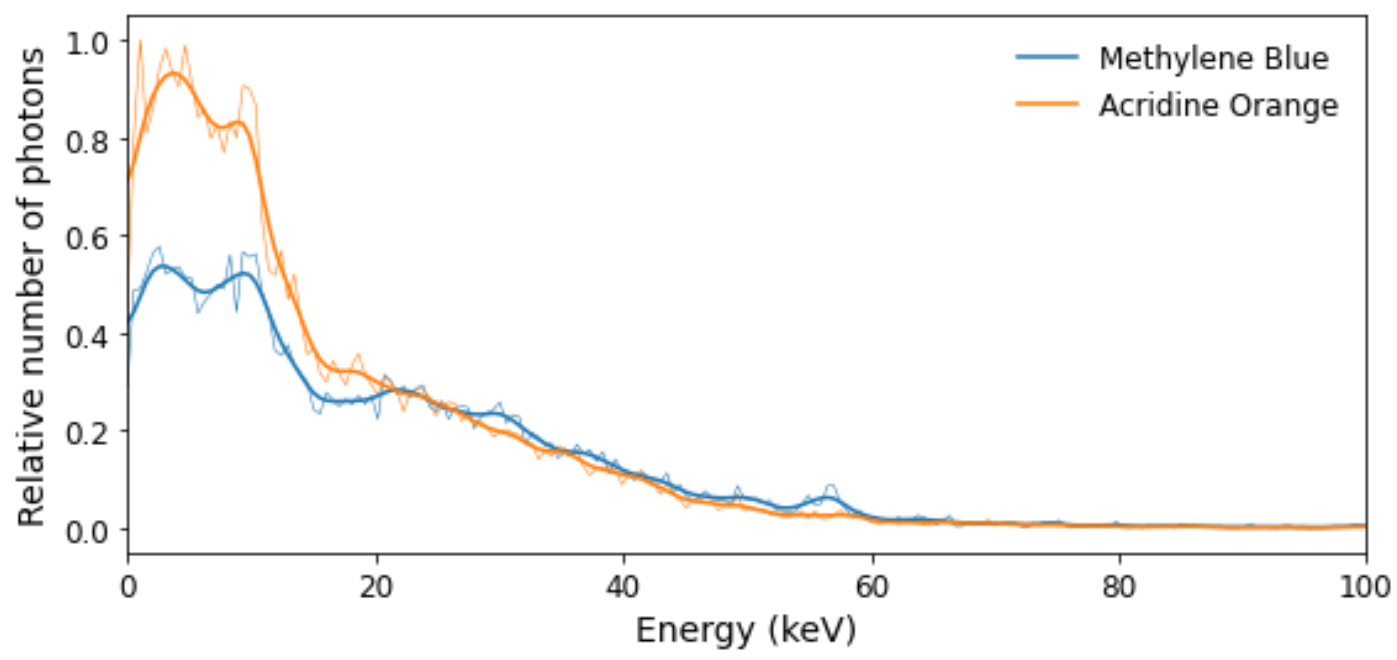

Figure 8: Energy spectrum of the secondary electrons at $5.0 \mathrm{~cm}$ depth, obtained for the second scenario. 


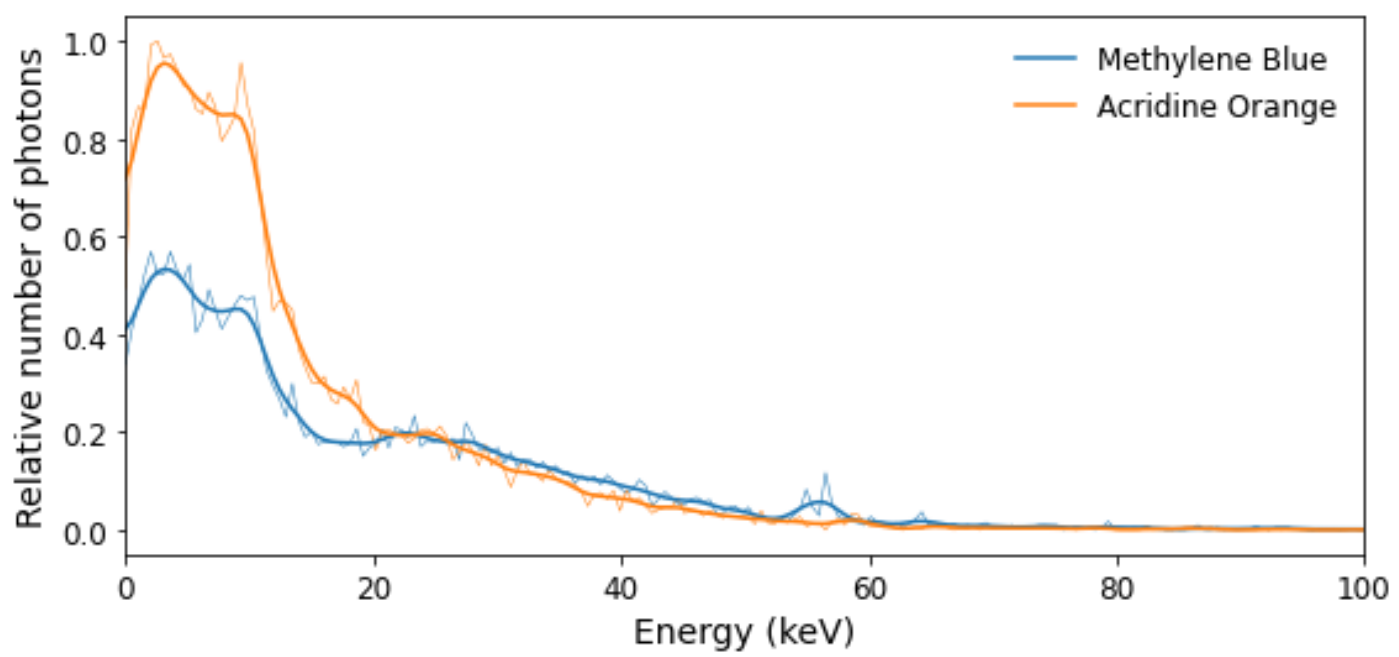

Figure 9: Energy spectrum of the secondary electrons at $9.0 \mathrm{~cm}$ depth, obtained for the second scenario.

\section{CONCLUSION}

The results show that interactions between x-rays and photosensitizers have a low probability to occur. Since only a small fraction of the $\mathrm{x}$-ray photons is affected by the addition of a photosensitizer in the irradiated medium, the x-ray energy spectra obtained for distinct photosensitizers remain mostly unchanged. These results suggest that the apparent effectiveness of using $\mathrm{x}$-rays combined with photosensitizers may be caused by the x-ray damage solely. In other words, the contribution of the photosensitizer in the obtained results may be minimal.

Regarding the comparison of setups 1 (tumor) and 2 (tumor + photosensitizer), for depths up to $3.5 \mathrm{~cm}$, the dose increase factor (DIF) was quite similar for both photosensitizers, being the acridine orange marginally higher than the methylene blue. However, from $5 \mathrm{~cm}$ up to the phantom's bottom, this trend is twisted, with the methylene blue showing a higher dose increase factor. In setup 3, the phantom was fully filled with the photosensitizer. Since x-ray interactions with the medium produce secondary electrons, with a yield that is proportional to the occurrence of such interactions, their energy spectra were used to compare the investigated cases. At shallow depths, the energy distribution of secondary electrons for both photosensitizing agents are nearly identical. However, for deeper penetration into the cylinder, if compared to the methylene blue, the acridine orange presents a higher yield of secondary electrons, with energies below $20 \mathrm{keV}$. These results 
suggest that the acridine orange may be a better XPDT photosensitizer, since it provides a more effective interaction with the $\mathrm{x}$-ray photons. However, many additional parameters, which were not considered in this work, must be taken into account, in order to state such affirmation. For example, the potential toxicity is a relevant aspect when selecting a photosensitizer. Given that acridine orange is an antitumor agent and bacterial mutagen, it can be toxic, if used in high concentrations [28]. This property cannot be evaluated in the Monte Carlo simulations here presented.

Since several limitations may be affecting the results and conclusions here presented, this work should be taken as a preliminary, first-order investigation of the $\mathrm{x}$-ray interactions with the acridine orange and methylene blue. Because only ionizing radiation processes were considered in the performed simulations, it was not possible to evaluate the emission of low-energy ( $\mathrm{eV})$ photons by fluorescence. Detection of fluorescence photons could be an indicative that photosensitizers were excited and activated to generate the reactive oxygen species. Moreover, there were many additional simplifications, such as, for example, the simple adopted geometry, and the homogeneous photosensitizer distribution. In an upcoming work, the contribution of non-ionizing radiation will be added, with particular interest in photons with energies below $100 \mathrm{eV}$. By including such interactions, it might be possible to verify if these secondary electrons could be somehow related to cytotoxic effects. In addition, since the fluorescence process is expected to be observable within the non-ionizing radiation energy range, it may be used to evaluate the activation of photosensitizers. 


\section{ACKNOWLEDGMENTS}

The authors acknowledge the CNPq (Chamada Universal 427273/2016-1) for providing the hardware used to perform the simulations here presented. In addition, the authors thank the Royal Society of Chemistry for the availability of "Fig 1. Principles of PDT", originally published in the article "Using X-rays in photodynamic therapy: an overview".

\section{REFERENCES}

[1] AGOSTINIS, P. et al. Photodynamic therapy of cancer: an update. CA: a cancer journal for clinicians, v. 61, n. 4, p. 250-281, 2011.

[2] LARUE, L. et al. Using X-rays in photodynamic therapy: an overview. Photochemical \& Photobiological Sciences, v. 17, n. 11, p. 1612-1650, 2018.

[3] BRAATHEN, L. R. et al. Guidelines on the use of photodynamic therapy for nonmelanoma skin cancer: an international consensus. Journal of the American Academy of Dermatology, v. 56, n. 1, p. 125-143, 2007.

[4] KURWA, H. A.; BARLOW, R. J. The role of photodynamic therapy in dermatology. Clinical and experimental dermatology, v. 24, n. 3, p. 143, 1999.

[5] FOOTE, Christopher S. Mechanisms of photosensitized oxidation. Science, v. 162, n. 3857, p. 963-970, 1968.

[6] KALKA, K.; MERK, H.; MUKHTAR, H. Photodynamic therapy in dermatology. Journal of the American Academy of Dermatology, v. 42, n. 3, p. 389-413, 2000.

[7] HENDERSON, B. W.; BUSCH, T. M.; SNYDER, J. W. Fluence rate as a modulator of PDT mechanisms. Lasers in Surgery and Medicine: The Official Journal of the American Society for Laser Medicine and Surgery, v. 38, n. 5, p. 489-493, 2006.

[8] ZHU, T. C.; FINLAY, J. C. The role of photodynamic therapy (PDT) physics. Medical physics, v. 35, n. 7Part1, p. 3127-3136, 2008. 
[9] BRANCALEON, L.; MOSELEY, H. Laser and non-laser light sources for photodynamic therapy. Lasers in medical science, v. 17, n. 3, p. 173-186, 2002.

[10] CAPELLA, M. A. M.; MENEZES, S. Synergism between electrolysis and methylene blue photodynamic action in Escherichia coli. International journal of radiation biology, v. 62, n. 3, p. 321-326, 1992.

[11] MATSUBARA, T. et al. Methylene blue in place of acridine orange as a photosensitizer in photodynamic therapy of osteosarcoma. In Vivo, v. 22, n. 3, p. 297-303, 2008.

[12] KUSUZAKI, K. et al. Acridine orange could be an innovative anticancer agent under photon energy. In Vivo, v. 21, n. 2, p. 205-214, 2007.

[13] HASHIGUCHI, S. et al. Acridine orange excited by low-dose radiation has a strong cytocidal effect on mouse osteosarcoma. Oncology, v. 62, n. 1, p. 85-93, 2002.

[14] KUSUZAKI, K. et al. Translational research of photodynamic therapy with acridine orange which targets cancer acidity. Current pharmaceutical design, v. 18, n. 10, p. 1414-1420, 2012.

[15] KUSUZAKI, K. et al. Clinical outcome of a novel photodynamic therapy technique using acridine orange for synovial sarcomas. Photochemistry and Photobiology, v. 81, n. 3, p. 705$710,2005$.

[16] KUSUZAKI, K. et al. Clinical trial of photodynamic therapy using acridine orange with/without low dose radiation as new limb salvage modality in musculoskeletal sarcomas. Anticancer research, v. 25, n. 2B, p. 1225-1235, 2005.

[17] NAKAMURA, T. et al. A new limb salvage surgery in cases of high-grade soft tissue sarcoma using photodynamic surgery, followed by photo-and radiodynamic therapy with acridine orange. Journal of surgical oncology, v. 97, n. 6, p. 523-528, 2008.

[18] MATSUBARA, T. et al. A new therapeutic modality involving acridine orange excitation by photon energy used during reduction surgery for rhabdomyosarcomas. Oncology reports, v. 21, n. 1, p. 89-94, 2009.

[19] MATSUBARA, T. et al. Clinical outcomes of minimally invasive surgery using acridine orange for musculoskeletal sarcomas around the forearm, compared with conventional limb salvage surgery after wide resection. Journal of surgical oncology, v. 102, n. 3, p. 271-275, 2010. 
[20] KUSUZAKI, K. et al. Clinical trial of radiotherapy after intravenous injection of acridine orange for patients with cancer. Anticancer Research, v. 38, n. 1, p. 481-489, 2018.

[21] PERL, J. et al. TOPAS: an innovative proton Monte Carlo platform for research and clinical applications. Medical physics, v. 39, n. 11, p. 6818-6837, 2012.

[22] POLUDNIOWSKI G. et al. SpekCalc: a program to calculate photon spectra from tungsten anode X-ray tubes. Physics in Medicine \& Biology, v.54, n.19, p. N433-N438, 2009.

[23] SPIGA, J. et al. Experimental benchmarking of Monte Carlo simulations for radiotherapy dosimetry using monochromatic X-ray beams in the presence of metal-based compounds. Physica Medica, v. 66, p. 45-54, 2019.

[24] ALVA-SÁNCHEZ, M.; PIANOSCHI, T. Study of the distribution of doses in tumors with hypoxia through the PENELOPE code. Radiation Physics and Chemistry, v. 167, p. 108428, 2020.

[25] TAKAHASHI, J.; MISAWA, M.; IWAHASHI, H. Combined treatment with X-ray irradiation and 5-aminolevulinic acid elicits better transcriptomic response of cell cycle-related factors than X-ray irradiation alone. International Journal of Radiation Biology, v. 92, n. 12, p. 774-789, 2016.

[26] KIM, S. et al. PubChem 2019 update: improved access to chemical data. Nucleic acids research, v. 47, n. D1, p. D1102-D1109, 2019.

[27] ACREE J. R.; W. E.; CHICKOS, J. S. Phase Transition Enthalpy Measurements of Organic and Organometallic Compounds, NIST Chemistry WebBook, NIST Standard Reference Database Number 69, PJ Linstrom and WG Mallard, Eds. National Institute of Standards and Technology, Gaithersburg, MD. Retrieved September, 2016.

[28] KUSUZAKI, K. et al. Total tumor cell elimination with minimum damage to normal tissues in musculoskeletal sarcomas following photodynamic therapy with acridine orange. Oncology, v. 59, n. 2, p. 174-180, 2000. 